\title{
Efficiency analysis of PV power plants shaded by MV overhead lines
}

\author{
Alberto Dolara $^{1}$ - George Cristian Lazaroiu ${ }^{2} \cdot$ Emanuele Ogliari $^{1}$
}

Received: 20 January 2016/Accepted: 11 April 2016/Published online: 30 April 2016

(c) The Author(s) 2016. This article is published with open access at Springerlink.com

\begin{abstract}
This paper deals with the occurrence of hot spot phenomena in photovoltaic (PV) systems under partial shading caused by objects on some parts of the modules. An interesting case of diffuse shadows is determined by overhead distribution lines whose path crosses or are in the proximity of the PV power plants. Investigating the impact of these shadows on reducing the power production of PV or on damaging the PV modules as the modules' temperature is increasing, is of high interest. At the SolarTech laboratory of Politecnico di Milano, the conditions for hot spot phenomena occurrence due to the overhead lines shading the PV cells were reproduced. Two experimental campaigns were carried out to investigate the currentvoltage and power-voltage characteristics, and the energy production. In each experimental campaign, the built shading structure was considered fixed and different shading conditions were created based on the natural displacement of the sun. The hot spot phenomena was revealed on a field PV installation in Italy, caused my medium voltage overhead lines shading the PV cells, using infrared imagery.
\end{abstract}

Keywords Photovoltaic · Hot spot phenomenon · Infrared imagery $\cdot$ Experimental analysis

George Cristian Lazaroiu

cristian.lazaroiu@upb.ro

Dipartimento di Energia, Politecnico di Milano, Milan, Italy

2 Department of Power Systems, University POLITEHNICA of Bucharest, Bucharest, Romania

\section{Introduction}

Under partial shading, the PV cell electrically operates as load, and the electrical power is transformed into heat causing the increase of temperature. The high temperature can damage the PV cell or can melt the welding, a phenomenon known as hot spot. The hot spot phenomena can lead to the irreversible damage of the cell and an important reduction of module power performances. The in-depth analysis of the most common defects of PV modules was carried out in [1].

Experimental measurements and simulations were carried out on four single cell modules for analyzing the actual temperature inside the module in the vicinity of hot spots in [2]. Simulation results demonstrated that hot spots located close to the PV module's edge have higher temperatures than the ones located in the module. Reference [3] presents four cases of hot spots in a real PV system, i.e., unwashed large bird droppings, dirt fixed at PV panel edges. Thermographic analysis was conducted in each case, revealing a temperature difference between shaded and non-shaded cells of approximately $19{ }^{\circ} \mathrm{C}$. Reference [4] presents the procedure methodology to carry out quality checks of infield PV systems connected to the grid. The thermal imaging was proved to be a baseline method to identify the faulted modules with hot spots caused by damaged cells. The influence of partial shading on the number of maximum power points was studied through simulations in [5], considering variations of the ambient parameters under shading occurrences. The obtained results were validated through experiments for establishing if the operating maximum power point (MPP) of the PV system is a local or global MPP [6, 7]. A hot spot phenomenon on a PV cell was revealed with a thermal camera under partial shading of this cell, the temperature exceeding $40{ }^{\circ} \mathrm{C}$ [8]. 
Electroluminescence and thermal imaging was used to highlight the hot spot effect occurrence, determined by reduced manufactured contact, over the bus-bars of two cells within a multi-crystalline silicon PV module [9]. Reference [10] proposes and experimentally validates a model to predict the hot spot temperatures in a PV module with 60 multi-crystalline silicon cells under shading conditions, in a climate controlled chamber.

In PV power plants, there are objects that are causing diffuse shadows on some areas of the modules. Among these, it is interesting the case determined by overhead distribution lines path crossing or in the vicinity of the PV plants (see Fig. 1). In PV field plants, some hot spot phenomena were recorded using the infrared imagery linked to the shadow of MV power lines. Understanding if these shadows determines a reduction of $\mathrm{PV}$ power production or are damaging the PV modules, considering the abnormal temperature behavior of the modules, is of high interest. However, the impact of shadows and hot spots on operational efficiency and lifetime of PV systems have been scarcely addressed in the scientific literature.

The conditions for reproducing the shading influence of overhead distribution lines on the PV modules were reconstructed at the SolarTech laboratory of Politecnico di Milano, Italy [11].

The conditions were analyzed for investigating the module I-V curves, but also the energy generation. The results reveal a deviation both of the temperature (with respect to the case without shading) and of the curve I-V.

The condition of more modules series connected can lead to situations where the power losses can be higher. In each experimental campaign, the built shading structure was considered fixed and different shading conditions were created based on the natural displacement of the sun. In addition, the electrical currents of a PV power plant were monitored and recorded; in particular the currents of some $\mathrm{PV}$ arrays connected in parallel, and the voltage (PV arrays affected or not by shading).

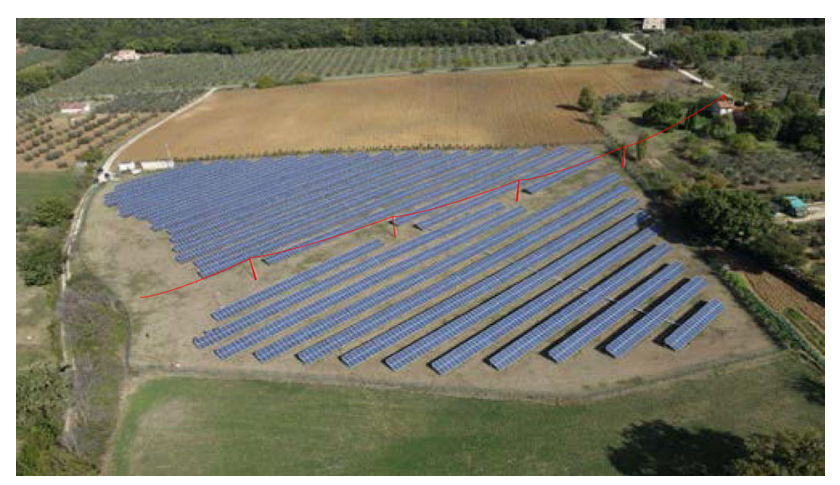

Fig. 1 PV plant in center of Italy crossed by a MV line

\section{Shading caused by an overhead wire}

The study of shading on a PV generator is usually based on the assumption that the sun is a point source of light placed at infinite distance from the PV generator surface. This approximation can be accepted as long as the objects causing shading appears from the PV generator surface point of view, much bigger than the solar disk. The apparent size, also known as angular diameter, is an angular measure that allows quantifying how large a sphere appears from a given point of view. The apparent size $\delta$ is defined as:

$\delta=2 \times \operatorname{tg}^{-1}\left(\frac{d}{2 \times D}\right)$

where $d$ is the actual diameter of the sphere and $D$ is the distance to the object. The idea of angular diameter is easy to extend to non-circular objects. For these, two measures are typically given: the major diameter, and the minor diameter. The 2D geometric model of the PV generator shaded by an overhead wire is shown in Fig. 2. In this case, the apparent size of the wire is defined as in (1), where $d$ is the diameter of the wire and $D$ is the distance between overhead wire and PV generator surface.

The diameter of the MV overhead lines wire is usually between 10 and $20 \mathrm{~mm}$, and their average height above the ground level is approximately $10 \mathrm{~m}$. Considering a distance between the PV modules and overhead wire between 5 and $10 \mathrm{~m}$, the minimum and maximum wire are $0.057^{\circ}$ and $0.23^{\circ}$, respectively.

The apparent size of the sun is approximately $0.53^{\circ}$. The model of Fig. 3, which takes into account the diameter of the sun, has to be considered for the study of the shading caused by the MV overhead line. The actual shading caused by the overhead wire consists of two regions. In the umbra (dark gray) region, the sun is completely obscured by the wire and no direct irradiation is present. In the penumbra (light gray) region, the sun is partially obscured by the wire and a reduced direct irradiation is present. Since the umbra has finite extent behind the wire, two kinds of shading can occur. The umbra reaches the PV module (as shown in Fig. 3a) if the apparent size of wire is higher than the apparent size of sun, otherwise (as shown in Fig. $3 b)$ the PV module is placed only in penumbra.

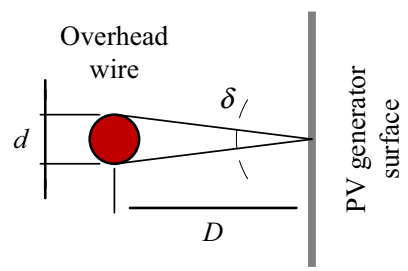

Fig. 2 Apparent size of wire 


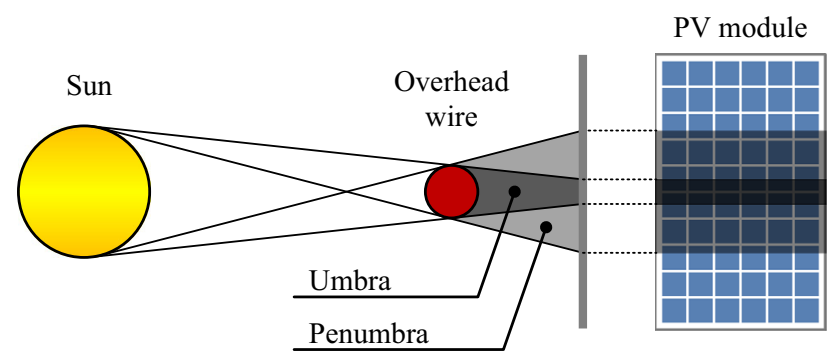

(a)

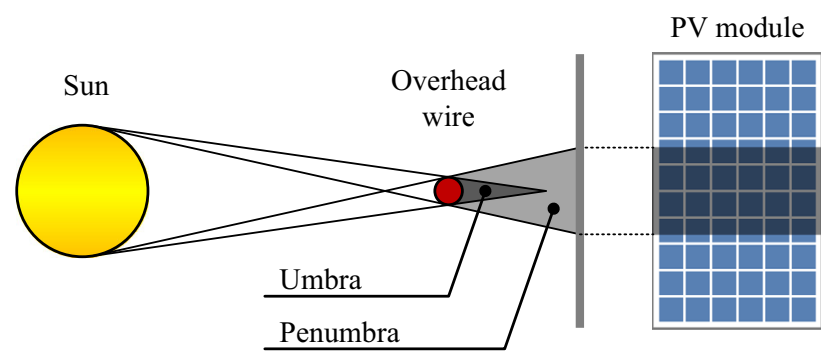

(b)

Fig. 3 Geometric model for the evaluation of the shading caused by the overhead wire

\section{Experimental setup and procedure of experiment}

The experimental campaign was carried out at Solar Tech Lab of Politecnico di Milano, Italy. The PV modules of the Solar Tech Lab are located as shown in Fig. 4. More information regarding the PV characteristics of Solar Tech Lab are presented in [12]. All modules are facing south, placed on a structure tilted at $30^{\circ}$ and with an azimuth of $6^{\circ}$ eastward. For the experimental campaign, the structure supporting the cable (outside diameter $30 \mathrm{~mm}$ ) that simulates the medium voltage overhead line wires was built and illustrated in Fig. 5. The structure supporting the cable has $3 \mathrm{~m}$ height. The apparent size of the cable is approximately $0.48^{\circ}$, therefore the partial shading of Fig. $3 \mathrm{~b}$ is reproduced. The shading tests were performed on a poly-crystalline PV module with 60 cells, three bypass diodes, and rated power of $245 \mathrm{~W}$.

Two typologies of experimental tests were performed:

- current-voltage characteristic. This test recorded the $I-$ $V$ curve in agreement with the requirements and

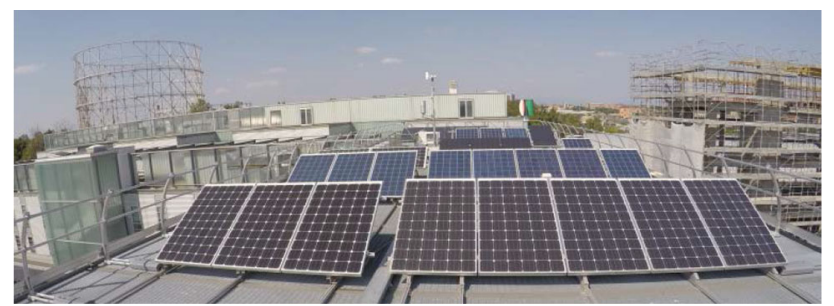

Fig. 4 PV modules installed at Solar Tech Lab, Politecnico di Milano

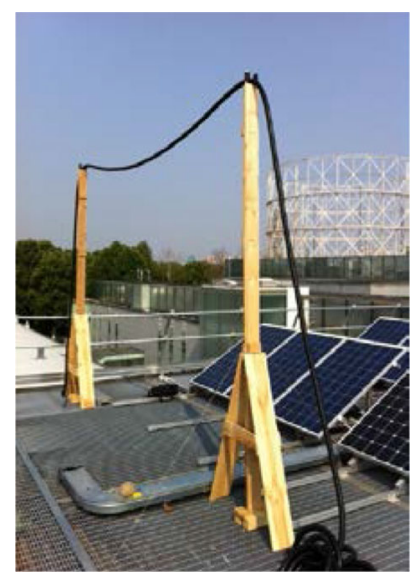

Fig. 5 Built structure for simulating medium voltage overhead lines shading

procedures stipulated in [13-15] and [4]. Different operating conditions and partial shadings were considered, and the $P-V$ curve was reproduced.

- energy production monitoring. In this test, each PV module was connected to the AC grid through a microinverter and the actual working condition (in term of $\mathrm{AC}$ and DC voltage), current and power were measured. The period of partial shading application was taken into account.

The weather conditions were monitored with a meteorological station equipped with sensors for solar radiation, temperature humidity and wind speed/direction [12]. Solar irradiation was measured with three different sensors: a net radiometer for the measurement of the direct normal irradiance (DNI) and two pyranometers for the measurement of total, respectively, diffuse irradiation on a horizontal plane.

\section{Current-voltage characteristic}

The $I-V$ curves were measured on the same PV module under different shading conditions created by the cable simulating the overhead wire and the natural displacement of the sun. Each $I-V$ curve of the PV module under analysis was obtained with a network analyser. The diagram of the measurement system is illustrated in Fig. 6. Detailed presentation of the measurement procedure is given in [12]. The $I-V$ curve measurements were performed every $5 \mathrm{~min}$ on clear-sky conditions. Each measurement follows the sequence:

- 10 consecutive measurements with the PV module under shading conditions; these measurements were then averaged to reduce uncertainty.

- the measurement of the $I-V$ curve (the 11th one), without shading on the PV panel surface, such that to 


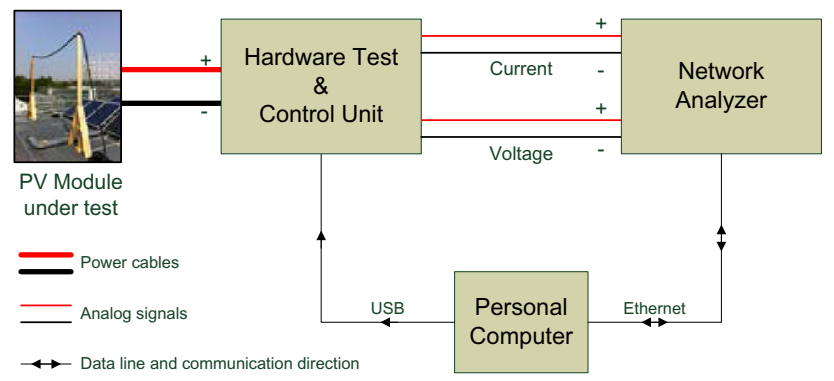

Fig. 6 Flowchart of the measuring system

obtain the $I-V$ reference characteristic of the module in case of temperature and irradiation conditions as for the previous measurements.

The shadow position during the monitoring campaign was registered through pictures (as shown in Fig. 7). During each measurement, the temperature of the PV module was measured using the Fluke Ti25 infrared thermo-camera [16]. In addition, the global irradiation on the PV surface was measured through the sensors of the meteorological station.

The obtained results are reported in Table 1 .

Figure 8 illustrates the $I-V$ and $P-V$ characteristics of reference (unshaded) and shaded PV modules at time instant 12:15. In addition, the value of the maximum power points in the shaded and reference conditions is reported. Figure 9 shows the values of the maximum power points (shadowed and reference) as a function of time from 11:00, when only one cell in the bottom left area of the module is partially shaded, to 13:00 when the shadow crosses on the whole PV module.

The analysis shows a minimum reduction of the $P_{\mathrm{MPP}}$ power when shading due to an overhead line occurs.

\section{Energy production monitoring results}

The energy production tests were carried out considering the cable, simulating the overhead wire, shading the PV
Table 1 Recorded data of the PV module

\begin{tabular}{lllllll}
\hline Time instant & $\begin{array}{l}\mathrm{I}_{\mathrm{MPP}} \\
\text { sh }\end{array}$ & $\begin{array}{l}\mathrm{V}_{\mathrm{MPP}} \\
\text { sh }\end{array}$ & $\begin{array}{l}\mathrm{P}_{\mathrm{MPP}} \\
\text { sh }\end{array}$ & $\begin{array}{l}\mathrm{I}_{\text {MPP }} \\
\text { meas }\end{array}$ & $\begin{array}{l}\mathrm{V}_{\text {MPP }} \\
\text { meas }\end{array}$ & $\begin{array}{l}\mathrm{P}_{\text {MPP }} \\
\text { meas }\end{array}$ \\
\hline 11.00 & 5.95 & 26.20 & 155.8 & 6.07 & 26.03 & 157.9 \\
11.15 & 6.31 & 25.85 & 163.2 & 6.39 & 25.88 & 165.3 \\
$11: 30$ & 6.77 & 25.55 & 172.9 & 6.73 & 25.74 & 173.2 \\
11.45 & 6.76 & 25.75 & 174.1 & 6.87 & 25.75 & 176.9 \\
$12: 00$ & 6.79 & 25.45 & 172.9 & 6.77 & 25.86 & 175.0 \\
$12: 15$ & 7.06 & 25.80 & 182.1 & 7.16 & 25.51 & 182.5 \\
$12: 30$ & 7.11 & 25.60 & 181.9 & 7.18 & 25.63 & 184.0 \\
$12: 45$ & 7.22 & 25.75 & 186.0 & 7.33 & 25.55 & 187.3 \\
\hline
\end{tabular}

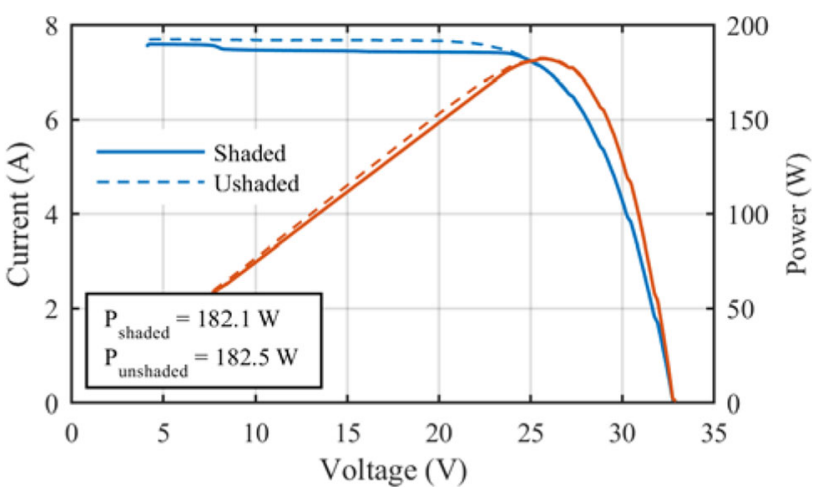

Fig. $8 I-V$ and $P-V$ characteristics of reference (unshaded) and shaded PV modules@12:15 during the experimental campaign

module connected at its inverter for the normal operation. The data were recorded using the monitoring software of the inverter. This test compared the PV module production under partial shading with the production of modules not affected by shading.

Figure 10 shows the power generated by a partially shaded PV module (blue line) and by unshaded PV modules (orange line). Figure 10 also illustrates the power difference among the due curves (red line).
Fig. 7 Shadow position during the experimental campaign (a), and thermal image of the same PV module (b) (brightness and contrast were optimized to highlight the shadow)

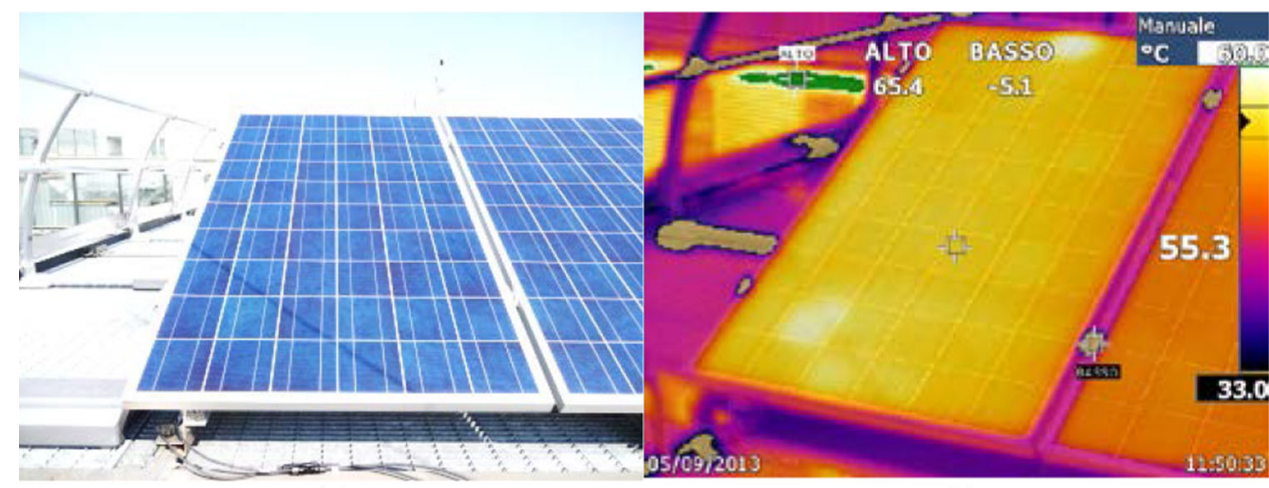

(a) (b) 
Figure 11 illustrates the thermal analysis performed with the infrared camera during this test. The experimental results reveal that an important decrease of power is not observed.

The partially shaded cells continue to operate as generators. The power trend is similar to the other modules without shading.

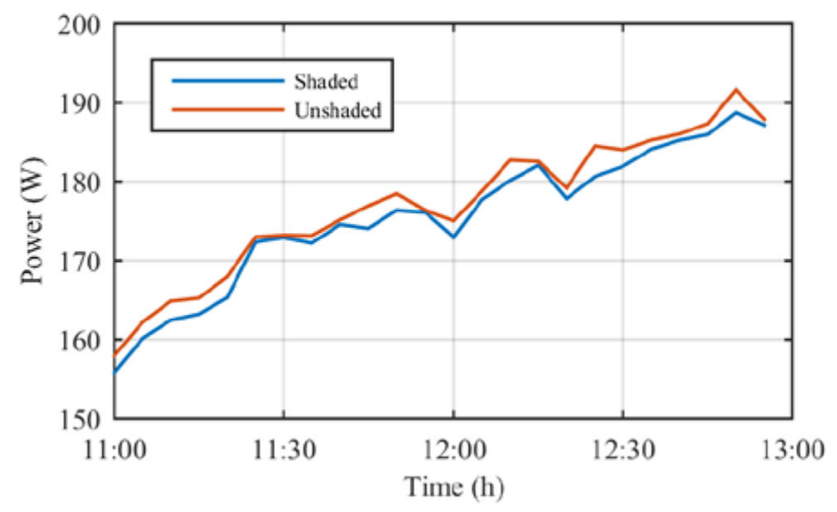

Fig. 9 Maximum power points in the shaded and reference conditions during the experimental campaign

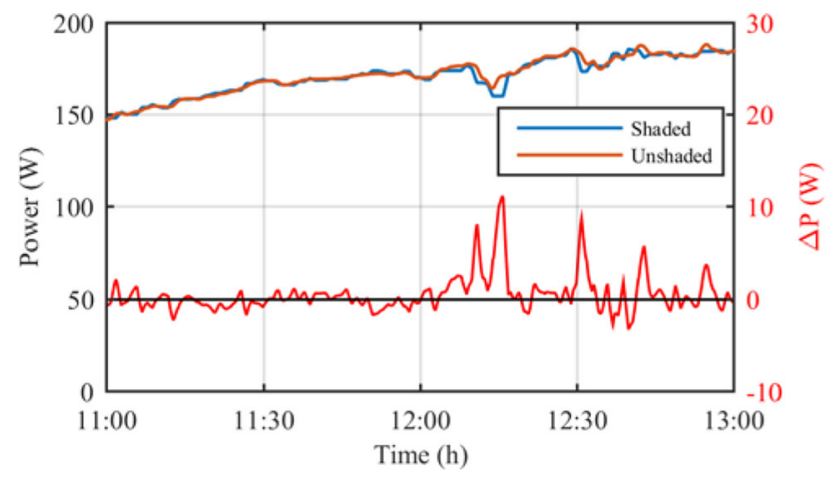

Fig. 10 Recorded input power for one shaded (blue line) and one unshaded (orange line) module, and comparison among them (right axes and red line)

\section{Field case study}

In a PV system located in the north-east part of Italy (see Figs. 12, 13), the hot spot phenomenon determined by the overhead MV line wires shading the PV cells was recorded (as shown in Figs. 14, 15). Figure 12 shows an overview of the PV plant: the wires of the MV line crossing the PV field and its poles are highlighted. Figure 13 shows the detail of the PV generator were hot spots were recorded. The path of the MV wires and the pole within the PV plant are highlighted; the eight strings, connected to the same string box, analyzed in this work, are identified.

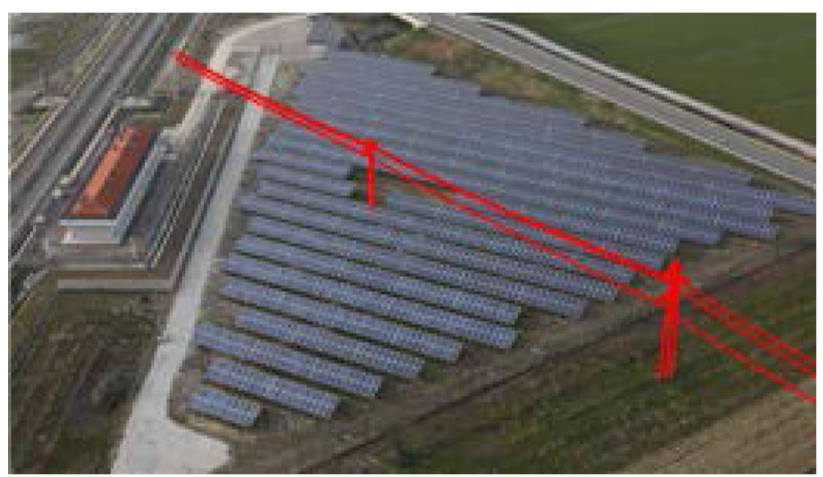

Fig. 12 PV plant crossed by a MV line under analysis

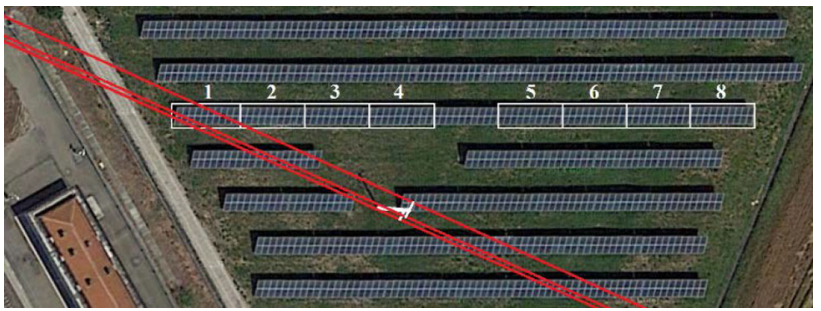

Fig. 13 Detail of the PV plant: the MV line, the pole and the strings under analysis are highlighted
Fig. 11 Picture (a) and thermal image (b) of the shaded module during energy test (brightness and contrast have been optimized to highlight the shadow)

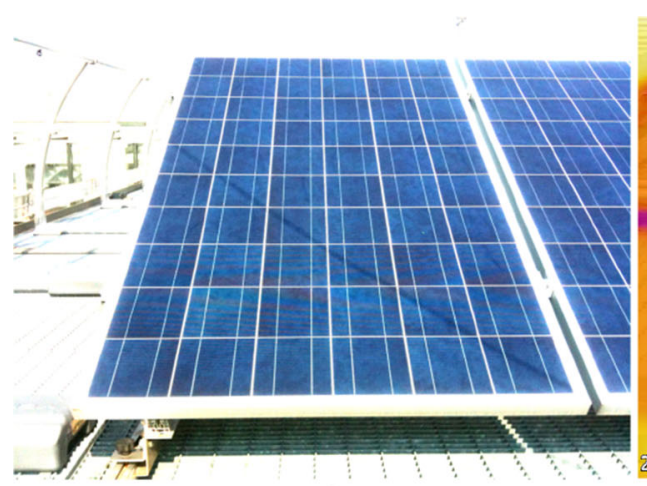

(a)

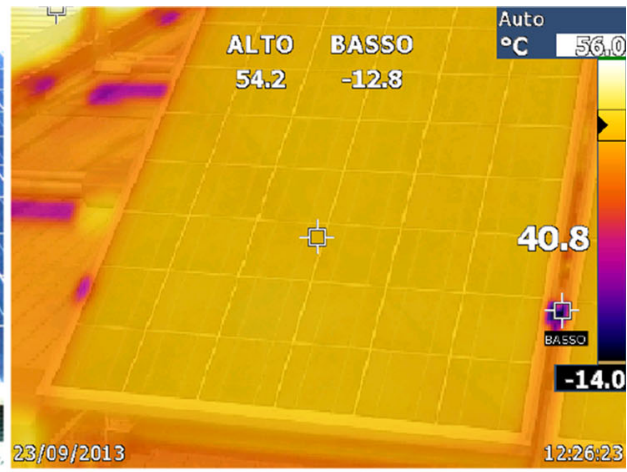

(b) 
Fig. 14 Image of the field test case: a visual inspection of PV system shaded by overhead lines, $\mathbf{b}$ thermal image of the PV systems highlighting the 4 points reported in Table 2
Fig. 15 Image of the field test case: a visual inspection of PV system shaded by overhead lines, $\mathbf{b}$ thermal image of the PV systems highlighting the 4 points reported in Table 3

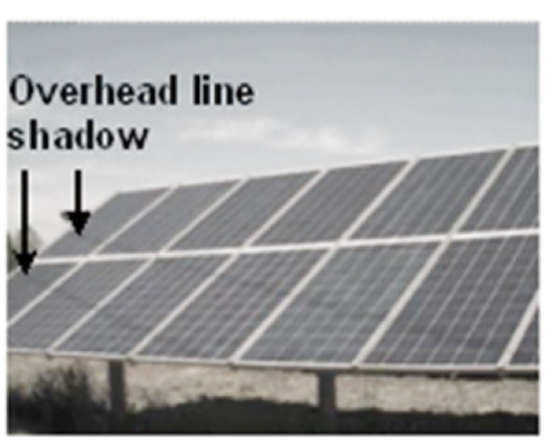

(a)

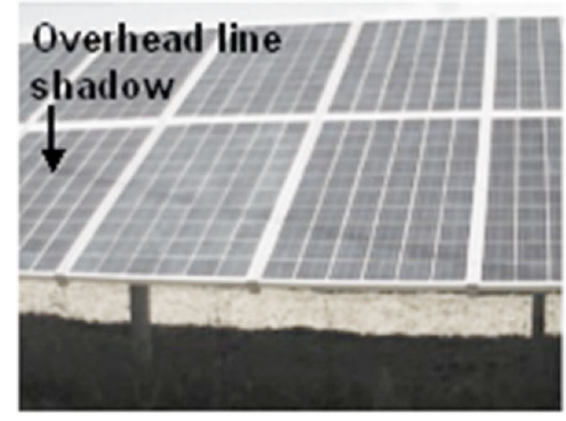

(a)

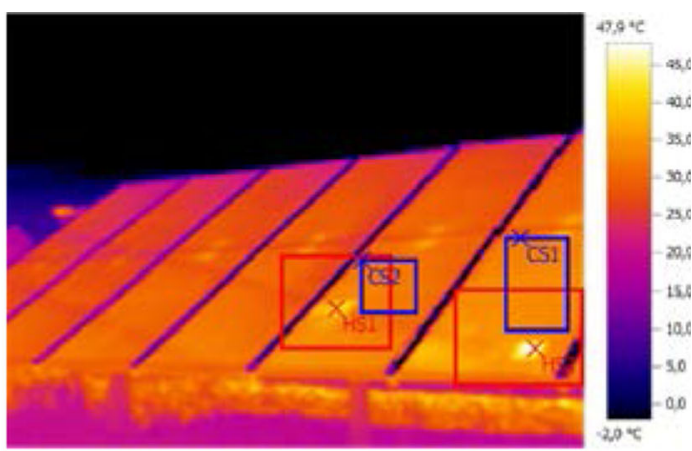

(b)

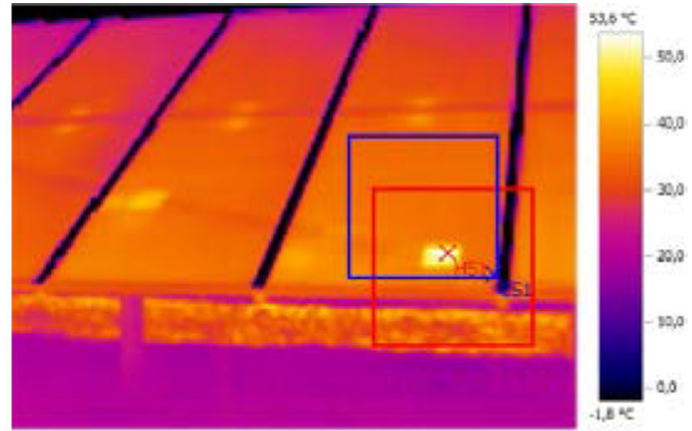

(b)

\section{PV plant and MV line main features}

The rated power of the aforementioned PV plant is about $1 \mathrm{MW}$, and it is connected to the MV grid through a single inverter. The PV generator is composed of about 200 strings, each of 20 modules connected in parallel. The parallel connection of the strings is carried out using the usual scheme based on two parallel levels. The first parallel level is made from the connection of groups of eight strings in smart string boxes distributed over the field. The second parallel level is made from the connection of each string box output to the DC input of the centralized inverter smart string boxes measure each string current and the common string voltage. The monitoring system stores the average value of these electrical measures every $15 \mathrm{~min}$. The MV line crossing the PV generator consists of three overhead wires with section of $150 \mathrm{~mm}^{2}$. The pole within the photovoltaic field is $12 \mathrm{~m}$ high. The height above ground level of the wires is approximately $10.5,11$ and $11.5 \mathrm{~m}$, respectively. The MV line and the surface of the PV modules are not parallel; the apparent size of the wires is evaluated taking into account the average distance between wires and the center of string \#1: it results approximately in $0.10^{\circ}$, and the partial shading of Fig. $3 b$ occurs.

\section{Thermal analysis}

The visual and thermal inspection was carried out on April 26, 2015 [17]. The analysis of the thermal images reveal the overheating of some cells shaded by the overhead line in the string \#1, and the most cold and most hot points are reported in Tables 2 and 3. The results reveal a hot spot temperature between 10 and $20^{\circ} \mathrm{C}$, and a small current reduction. This is in agreement with [18]. In fact, not all the modules presenting a hot spot with a higher temperature than the average temperature of the module between 10 and $20{ }^{\circ} \mathrm{C}$ have an effective power loss (measured as a decrease in the operating voltage in relation to a non-defective/ shaded module of the same string).

\section{Electrical analysis}

The string currents and voltages were monitored and recorded for a period of 2 years. The analysis of these electrical quantities focuses on the input currents of the string box where one or more strings are affected by the shading created by the overhead line wires, while the others are unshaded. Figure 16 shows the input currents of the string box, measured during the day when the hot spot phenomenon was recorded. Despite the presence of shading on the PV modules, the current generated 
Table 2 Recorded cell parameters on $26 / 04$ / 2015@13:44:40
Table 3 Recorded cell parameters on $26 / 04 /$ 2015@13:45:00

\begin{tabular}{llll}
\hline & Temperature $\left({ }^{\circ} \mathrm{C}\right)$ & Emissivity degree & Reflected temperature $\left({ }^{\circ} \mathrm{C}\right)$ \\
\hline Most cold point 1 (CS1) & 31.4 & 0.94 & 20 \\
Most cold point 2 (CS2) & 30.7 & 0.94 & 20 \\
Most warm point 1 (HS1) & 41.4 & 0.94 & 20 \\
Most warm point 2 (HS2) & 47.9 & 0.94 & 20 \\
\hline
\end{tabular}

\begin{tabular}{llll}
\hline & Temperature $\left({ }^{\circ} \mathrm{C}\right)$ & Emissivity degree & Reflected temperature $\left({ }^{\circ} \mathrm{C}\right)$ \\
\hline Most cold point 1 (CS1) & 32.7 & 0.94 & 20 \\
Most warm point 1 (HS1) & 53.6 & 0.94 & 20 \\
\hline
\end{tabular}

by string \# 1 is very close to the current generated by the other seven unshaded strings.

Figure 17 shows the currents of the shaded string and the unshaded one (string \#8 taken as reference) during a sunny day, while Fig. 18 shows the same measures recorded during a partial cloudy day. Partial shading occurs between 10:00 and 15:00. In both cases, no significant current reduction of the partially shaded string is observed.

\section{Study of shadows}

In addition to the overhead wires of the three-phase MV line, near objects and structures draw visible shades on the

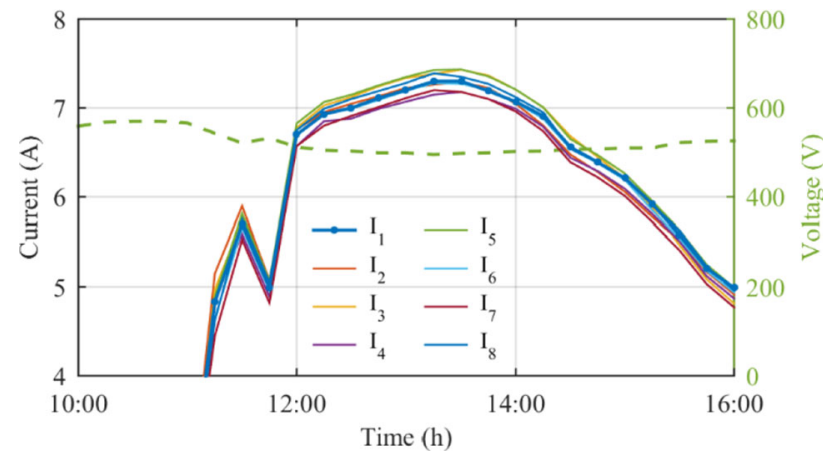

Fig. 16 String current and voltage measured on April 26, 2015

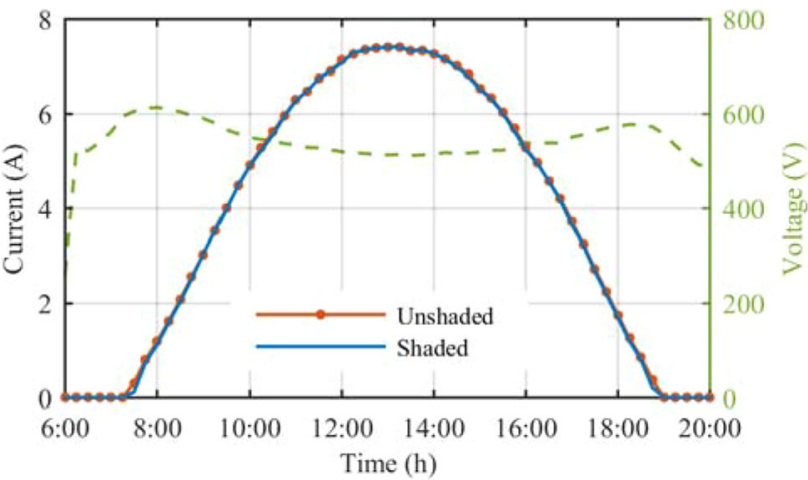

Fig. 17 String current and voltage measured during a sunny day

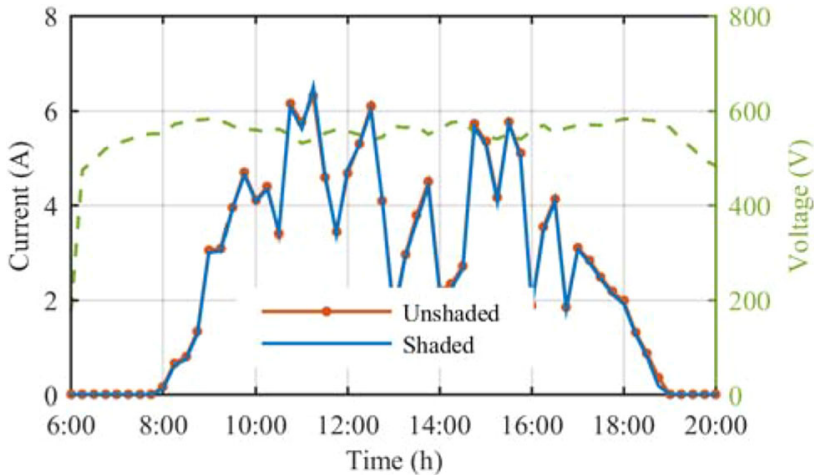

Fig. 18 String current and voltage measured during a partially cloudy day

PV field. Near shading on one or more strings analyzed in this work are caused by:

- the pole of the MV line within the PV field;

- the front row array;

- the metallic fence and poles for CCTV cameras and lighting system, on the perimeter of the PV field;

- the building just across the border of the PV field.

Vicinity shading changes with month and time of the day, and it has an effect on the PV strings here analyzed only in the winter months. Figure 19 shows the currents and the voltage of the PV strings in a sunny winter day (January 28). Early in the morning, the front row shadowing and the vicinity shadow caused by the pole of the MV line within the PV field affects all the strings from \#1 to \#7. From dawn to hour 9:15 only string \#8, at the east side of the array, is always unshaded. The morning front row shadowing ends completely at 9:45 h. The shadow of the MV line pole within the PV field causes a reduction in the current produced by string \#3 until $10: 30 \mathrm{~h}$ and by string \#4 from 10:15 to $12: 00 \mathrm{~h}$. In the afternoon, the shading produced by a pole near the string \#1 causes the string current reduction about half an hour before the afternoon front row shadowing, at about 15:30 h. From 15:30 to $16: 30 \mathrm{~h}$ only string \#1 and string \#2, at the west 


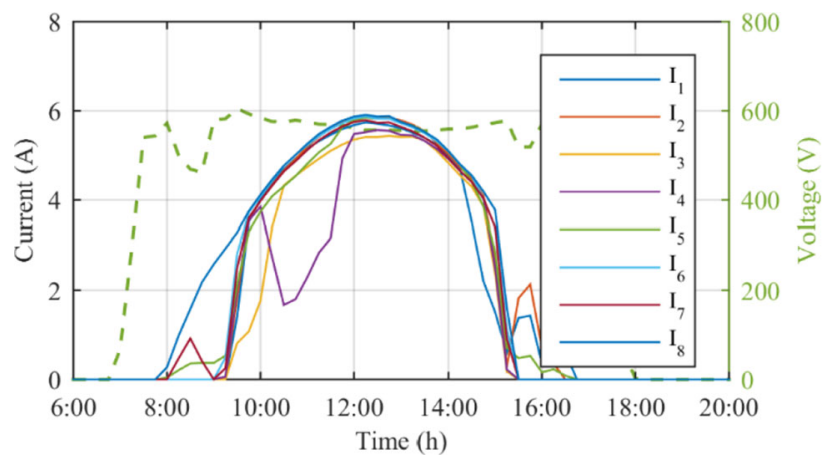

Fig. 19 String currents and voltage measured on January 28, 2015

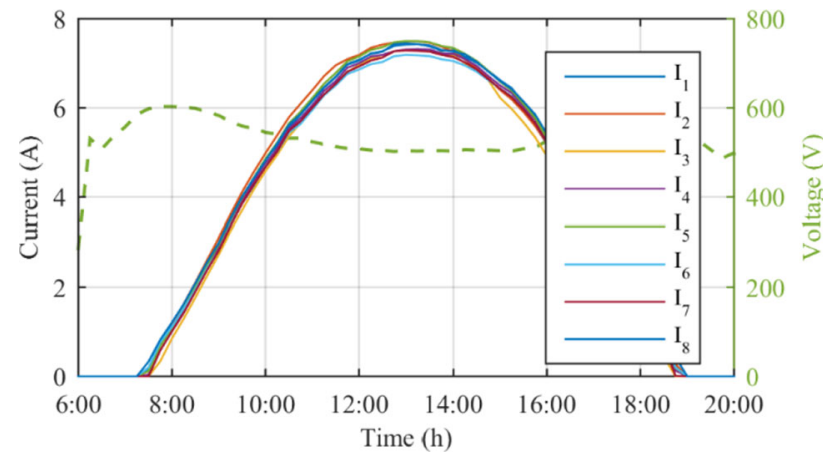

Fig. 20 String currents and voltage measured on April 21, 2015

side of the array, are unshaded. Figure 20 shows the currents and the voltage of the PV strings in a sunny spring day (April 21). There is no partial shading caused by nearby objects or structures.

Vicinity shadings and the shading caused by the wires crossing the PV field give rise to different effects. Vicinity shadings have a direct impact on the string current, while the shading caused by the overhead wires does not lead to a significant reduction in the photo-generated current. Moreover, nearby shadings occur only in the winter months, while the shading caused by the overhead wires occurs all over the year.

\section{Conclusions}

The experimental analysis conducted within the SolarTechLab demonstrated the conditions for hot spot phenomenon occurring during the normal operation of the PV modules under shading due to overhead line wires with a path crossing the PV field.

The tests results reveal a small reduction of MPP for the shaded module compared with the MPP of PV module without shading, for the same temperature and under uniform irradiation. During the measurement of the $I-$ $V$ curves, a small temperature increase was registered only for the shaded cells. In addition, the results of energy tests did not reveal a significant reduction of generated energy, within the same observation period, of the shaded PV modules compared with the ones without shading.

Furthermore, the string currents and voltages in a real PV plant affected by shading due to an overhead power line were monitored and recorded for a period of 2 years. Also in this case no evidence in power reduction was recorded.

Further developments of the conducted analysis focus on various connection configurations of the PV modules and the validation, with thermal models developed for PV modules, of the temperature reached by the cells affected by the hot spot phenomenon.

Open Access This article is distributed under the terms of the Creative Commons Attribution 4.0 International License (http://crea tivecommons.org/licenses/by/4.0/), which permits unrestricted use, distribution, and reproduction in any medium, provided you give appropriate credit to the original author(s) and the source, provide a link to the Creative Commons license, and indicate if changes were made.

\section{References}

1. Djordjevic, S., Parlevliet, D., Jennings, P.: Detectable faults on recently installed solar modules in Western Australia. Renew. Energy 67, 215-221 (2014)

2. Solheim, H.J., Fjær, H.G., Sørheim, E.A., Foss, S.E.: Measurement and simulation of hot spots in solar cells. Energy Procedia 38, 183-189 (2013)

3. Solorzano, J., Egido, M.A.: Hot spot mitigation in PV arrays with distributed MPPT (DMPPT). Sol. Energy 101, 131-137 (2014)

4. Muñoz, J.V., Nofuentes, G., Aguilera, J., Fuentes, M., Vidal, P.G.: Procedure to carry out quality checks in photovoltaic gridconnected systems: six cases of study. Appl. Energy $\mathbf{8 8}(8)$, 2863-2870 (2011)

5. Mäki, A., Valkealahti, S.: Differentiation of multiple maximum power points of partially shaded photovoltaic power generators. Renew. Energy 71, 89-99 (2014)

6. Qi, J., Zhang, Y., Chen, Y.: Modeling and maximum power point tracking (MPPT) method for PV array under partial shade conditions. Renew. Energy 66, 337-345 (2014)

7. Paraskevadak, E.V., Papathanassiou, S.A.: Evaluation of MPP voltage and power of mc Si PV modules in partial shading conditions. IEEE Trans. Energy Convers. 26, 923-932 (2011)

8. Zegaouia, A., Petita, P., Ailleriea, M., Sawickia, J.P., Charlesa, J.P.: Experimental validation of photovoltaic direct and reverse mode model. Influence of partial shading. Energy Procedia 18, 1247-1253 (2012)

9. Crozier, J.L., van Dyk, E.E., Vorster, F.J.: Characterization of cell mismatch in a multi crystalline silicon photovoltaic module. In: Proceedings 4th South African Conference on Photonic Materials, Physica B: Condensed Matter, vol. 407, no. 10, pp. 1578-158115 (2012)

10. Geisemeyer, I., Fertig, F., Warta, W., Rein, S., Schubert, M.C.: Prediction of silicon PV module temperature for hot spots and worst case partial shading situations using spatially resolved lockin thermography. Solar Energy Mater. Solar Cells 120(part A), 259-269 (2014)

11. Dolara, A., Leva, S., Manzolini, G.: Comparison of different physical models for PV power output prediction. Sol. Energy 119, 83-99 (2015) 
12. Dolara, A., Lazaroiu, G.C., Leva, S., Manzolini, G.: Experimental investigation of partial shading scenarios on $\mathrm{PV}$ (photovoltaic) modules. Energy 55, 466-475 (2013)

13. Photovoltaic devices. Part 1: measurements of photovoltaic current-voltage characteristics. IEC Std. 60904-1 (2006)

14. Photovoltaic devices. Procedures for temperature and irradiance corrections to measured I-V characteristics. IEC Std. 60891 (2010)

15. Photovoltaic (PV) systems. Requirements for testing, documentation and maintenance. Part 1: Grid connected systems. Documentation, commissioning tests and inspection. IEC Std. 62446-1 (2016)
16. Grimaccia, F., Aghaei, M., Mussetta, M., Leva, S., Bellezza Quater, P.: Planning for PV plant performance monitoring by means of unmanned aerial systems (UAS). Int J Energy Environ Eng 6(1), 47-54 (2015)

17. Aghaei, M., Grimaccia, F., Gonano, C.A., Leva, S.: Innovative automated control system for PV fields inspection and remote control. IEEE Trans. Ind. Electron. 62(11), 7287-7296 (2015)

18. Moreton, R., Lorenzo, E., Narvarte, L.: Experimental observations on hot spots and derived acceptance/rejection criteria. Sol. Energy 118, 28-40 (2015) 